\title{
Leptin modulates electrophysiological characteristics and isoproterenol-induced arrhythmogenesis in atrial myocytes
}

Yung-Kuo Lin ${ }^{1,2}$, Yao-Chang Chen ${ }^{3}$, Jen-Hung Huang ${ }^{1}$, Yenn-Jiang Lin ${ }^{4}$, Shiang-Suo Huang ${ }^{5,6}$, Shih-Ann Chen ${ }^{4}$ and Yi-Jen Chen ${ }^{1,2^{*}}$

\begin{abstract}
Background: Obesity is an important risk factor for atrial fibrillation (AF). Leptin is an important adipokine. However, it is not clear whether leptin directly modulates the electrophysiological characteristics of atrial myocytes.

Results: Whole cell patch clamp and indo-1 fluorescence were used to record the action potentials (APs) and ionic currents in isolated rabbit left atrial (LA) myocytes incubated with and without (control) leptin (100 nM) for $1 \mathrm{~h}$ to investigate the role of leptin on atrial electrophysiology. Leptin-treated LA myocytes $(n=19)$ had longer $20 \%$ of AP duration ( $28 \pm 3$ vs. $21 \pm 2 \mathrm{~ms}, \mathrm{p}<0.05$ ), but similar $50 \%$ of AP duration ( $51 \pm 4$ vs. $50 \pm 3 \mathrm{~ms}, \mathrm{p}>0.05$ ), and $90 \%$ of AP duration ( $89 \pm 5$ vs. $94 \pm 4 \mathrm{~ms}, p>0.05)$, as compared to the control $(n=22)$. In the presence of isoproterenol $(10 \mathrm{nM})$, leptin-treated LA myocytes $(n=21)$ showed a lower incidence $(19 \%$ vs. $54.2 \%, p<0.05)$ of delayed afterdepolarization (DAD) than the control $(n=24)$. Leptin-treated LA myocytes showed a larger sodium current, but a smaller ultra-rapid delayed rectifier potassium current, and sodium-calcium exchanger current than the control. Leptin-treated and control LA myocytes exhibited a similar late sodium current, inward rectifier potassium current, transient outward current and L-type calcium current. In addition, the leptin-treated LA myocytes $(n=38)$ exhibited a smaller intracellular $\mathrm{Ca}^{2+}$ transient $(0.21 \pm 0.01$ vs. $0.26 \pm 0.01 \mathrm{R} 410 / 485, \mathrm{p}<0.05)$ and sarcoplasmic reticulum $\mathrm{Ca}^{2+}$ content $(0.35 \pm 0.02$ vs. $0.43 \pm 0.03$ R410/485, $\mathrm{p}<0.05)$ than the control LA myocytes $(n=42)$.
\end{abstract}

Conclusions: Leptin regulates the LA electrophysiological characteristics and attenuates isoproterenol-induced arrhythmogenesis.

Keywords: Adipokines, Atrial fibrillation, Epicardial fat, Leptin, Obesity

\section{Background}

Obesity is an independent risk factor for the genesis of $\mathrm{AF}$ [1-4]. Atrial fibrillation (AF) is the most prevalent cardiac arrhythmia in clinical practice which can induce cardiac dysfunction and stroke [5]. Obesity increase the prevalence of hypertension, ischemic heart disease, congestive heart failure, and ventricular dysfunction, which can contribute to the development of AF [6-9]. In addition, epicardial fat can change cardiac electrophysiology by

\footnotetext{
* Correspondence: a9900112@ms15.hinet.net

'Division of Cardiovascular Medicine, Department of Internal Medicine, Wan Fang Hospital, Taipei Medical University, 111, Hsin-Lung Road, Sec. 3, Taipei, Taiwan

${ }^{2}$ Graduate Institute of Clinical Medicine, College of Medicine, Taipei Medical University, Taipei, Taiwan

Full list of author information is available at the end of the article
}

increasing inflammation, mechano-electrical regulation and adipocyte-myocytes interaction [10]. Adipose tissues can produce many adipokines, which may have electrophysiolgical effects through changing action potential morphology, ionic profiles and contractility in the atrium $[11,12]$. However, it is not clear which adipokine is responsible for the cardiac effects of adipose tissues.

Leptin is a peptide hormone that is expressed in adipose tissue, and that regulates body weight through the inhibition of food intake and promotion of energy expenditure $[13,14]$. However, leptin can also be produced in the heart, and function in an autocrine and paracrine manner [15,16]. Leptin plasma concentrations are increased in insulin-resistant states, such as obesity and

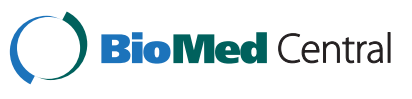

(c) 2013 Lin et al.; licensee BioMed Central Ltd. This is an Open Access article distributed under the terms of the Creative Commons Attribution License (http://creativecommons.org/licenses/by/2.0), which permits unrestricted use, distribution, and reproduction in any medium, provided the original work is properly cited. The Creative Commons Public Domain Dedication waiver (http://creativecommons.org/publicdomain/zero/1.0/) applies to the data made available in this article, unless otherwise stated. 
hypertension [17-19]. Similarly, leptin concentrations are elevated in patients with heart disease such as ischemic heart disease and congestive heart failure [20,21]. However, clinical studies have yielded inconsistent results on the association of leptin with cardiovascular disease $[20,22]$. Evidences have indicated that leptin may have either adverse or beneficial effects on the heart and the vascular system [23-27]. In addition, leptin is considered a novel link between obesity, diabetes, cardiovascular risks and ventricular hypertrophy [28]. Leptin signaling has been shown to contribute to atrial fibrosis and angiotensin II-evoked AF [29]. These findings suggest that leptin may play a critical role in cardiac electrophysiology. The purpose of this study was to investigate the effect of leptin on the electrophysiological characteristics of atria myocytes and its role in atrial arrhythmogenesis.

\section{Methods}

\section{Isolation of single LA myocytes}

All animal experimental procedures were approved by the Institutional Animal Care and Use Committee (IACUC) at Taipei Medical University (Protocol Number LAC-1000127) and conform to the institutional Guide for the Care and Use of Laboratory Animals and the Guide for the Care and Use of Laboratory Animals published by the US National Institutes of Health (NIH Publication No. 85-23, revised 1996). Male rabbits (1 to $2 \mathrm{~kg}$ ) were intravenously injected with sodium pentobarbital $(100 \mathrm{mg} / \mathrm{kg})$. After anesthetization, the hearts were immediately removed and mounted on a Langendorff apparatus to perform retrograde perfusion of oxygenated normal Tyrode's solution at $37^{\circ} \mathrm{C}$ containing (in $\mathrm{mM}$ ): $\mathrm{NaCl} 137, \mathrm{KCl} 5.4, \mathrm{CaCl}_{2} 1.8, \mathrm{MgCl}_{2}$ 0.5 , HEPES 10 and glucose 11; adjusted to $\mathrm{pH} 7.4$ with $\mathrm{NaOH}$. After the hearts were cleaned of blood, the perfusate was replaced with oxygenated $\mathrm{Ca}^{2+}$-free Tyrode's solution containing 300 units/ml collagenase type I (Sigma Chemical, St, Louis, MO) and 0.25 units/ml protease type XIV (Sigma) for approximately 8 to12 min. The left atrium (LA) was excised and gently shaken in $50 \mathrm{ml}$ of $\mathrm{Ca}^{2+}$-free oxygenated Tyrode's solution until single cardiomyocytes were obtained. The solution was then gradually changed to normal oxygenated Tyrode's solution. The myocytes were allowed to stabilize in the bath for at least $30 \mathrm{~min}$ before the experiments.

\section{Electrophysiological study}

A whole-cell patch clamp was performed in the LA myocyte with and without (control) incubation of leptin (100 nM) for $1 \mathrm{~h}$ using an Axopatch 1D amplifier (Axon Instruments, CA, USA) at $35 \pm 1^{\circ} \mathrm{C}$ as described previously $[11,30,31]$. Borosilicate glass electrodes (o.d., $1.8 \mathrm{~mm}$ ) were used, with tip resistances of $\sim$ approximately 3 to $5 \mathrm{M} \Omega$. Before formation of the membrane-pipette seal, the tip potentials were zeroed in Tyrode's solution.
Junction potentials between the bath and pipette solution $(9 \mathrm{mV})$ were corrected for action potential (AP) recordings. APs were recorded in the current-clamp mode, and ionic currents were measured in the voltage-clamp mode. A small hyperpolarizing step from a holding potential of $-50 \mathrm{mV}$ to a testing potential of $-55 \mathrm{mV}$ for $80 \mathrm{~ms}$ was delivered at the beginning of each experiment. The area under the capacitive currents was divided by the applied voltage step to obtain the total cell capacitance. Normally, 60\%-80\% series resistance $\left(R_{s}\right)$ was electronically compensated. The resting membrane potential (RMP) was measured during the period between the last repolarization and the onset of the subsequent AP. The AP amplitude (APA) was obtained from the measurement of RMP to the peak of the AP depolarization. AP durations were measured at $20 \%\left(\mathrm{APD}_{20}\right), 50 \%\left(\mathrm{APD}_{50}\right)$, and $90 \%\left(\mathrm{APD}_{90}\right)$ repolarization of the amplitude at a driven rate of $1 \mathrm{~Hz}$. DADs (delayed afterdepolarizations) were defined as the presence of a spontaneous depolarization of the impulse after full repolarization had occurred.

Micropipettes were filled with a solution containing the following (in $\mathrm{mM}$ ): $\mathrm{CsCl} 130, \mathrm{MgCl}_{2} 1, \mathrm{Mg}_{2} \mathrm{ATP} 5$, HEPES 10, EGTA 10, NaGTP 0.1, and $\mathrm{Na}_{2}$ phosphocreatine 5 , titrated to a $\mathrm{pH}$ of 7.2 with $\mathrm{CsOH}$ for the experiments on the L-type calcium current $\left(I_{\mathrm{Ca}-\mathrm{L}}\right)$; containing (in $\mathrm{mM}$ ) $\mathrm{CsCl} 133, \mathrm{NaCl} 5$, EGTA 10, $\mathrm{Mg}_{2} \mathrm{ATP} 5$, TEACl 20, and HEPES 5 ( $\mathrm{pH} 7.3$ with $\mathrm{CsOH}$ ) for the sodium current $\left(I_{\mathrm{Na}}\right)$; containing (in $\left.\mathrm{mM}\right) 10 \mathrm{NaCl}, 130 \mathrm{CsCl}, 5$ EGTA, 5 HEPES, 5 glucose, and 5 ATP-Mg for the late sodium current $\left(I_{\text {Na-Late }}\right)$; containing (in $\mathrm{mM}$ ) $\mathrm{NaCl} 20$, $\mathrm{CsCl} 110, \mathrm{MgCl}_{2}$ 0.4, $\mathrm{CaCl}_{2} 1.75$, tetraethylammonium chloride (TEACl) 20, BAPTA 5, glucose 5, Mg 2 ATP 5, and HEPES 10, titrated to a $\mathrm{pH}$ of 7.25 with $\mathrm{CsOH}$ for the experiments on sodium-calcium exchanger (NCX) current; and containing (in $\mathrm{mM}$ ) $\mathrm{KCl} 20, \mathrm{~K}$ aspartate 110 , $\mathrm{MgCl}_{2} 1, \mathrm{Mg}_{2}$ ATP 5, HEPES 10, EGTA 0.5, LiGTP 0.1, and $\mathrm{Na}_{2}$ phosphocreatine 5 , titrated to a $\mathrm{pH}$ of 7.2 with $\mathrm{KOH}$ for the experiments on the AP and potassium currents.

The $I_{\mathrm{Na}}$ was recorded during depolarization from a holding potential of $-120 \mathrm{mV}$ to testing potentials ranging from -90 to $0 \mathrm{mV}$ in $10-\mathrm{mV}$ steps for $40 \mathrm{~ms}$ at a frequency of $3 \mathrm{~Hz}$ at room temperature $\left(25 \pm 1^{\circ} \mathrm{C}\right)$ with an external solution containing (in $\mathrm{mM}$ ): $\mathrm{NaCl} 5, \mathrm{CsCl}$ 133, $\mathrm{MgCl}_{2} 2, \mathrm{CaCl}_{2}$ 1.8, nifedipine 0.002, HEPES 5 and glucose 5 with a pH of 7.3. The $I_{\text {Na-Late }}$ was recorded at room temperature with an external solution containing (in $\mathrm{mM}$ ): $140 \mathrm{NaCl}, 5 \mathrm{CsCl}, 2.0 \mathrm{MgCl}_{2}, 1.8 \mathrm{CaCl}_{2}, 5$ HEPES, 5 glucose, and 0.002 of nicardipine. The amplitude of the $I_{\text {Na-Late }}$ was measured at a voltage of $-20 \mathrm{mV}$ as the mean current amplitude between 200 and $250 \mathrm{~ms}$ after the membrane was depolarized by a $2,000-\mathrm{ms}$ pulse from -140 to $-20 \mathrm{mV}$.

The $I_{\mathrm{Ca}-\mathrm{L}}$ was measured as an inward current during depolarization from a holding potential of $-50 \mathrm{mV}$ to 
testing potentials ranging from -40 to $+60 \mathrm{mV}$ in $10-\mathrm{mV}$ steps for $300 \mathrm{~ms}$ at a frequency of $0.1 \mathrm{~Hz}$ using a perforated patch clamp with amphotericin $\mathrm{B}$. The $\mathrm{NaCl}$ and $\mathrm{KCl}$ in the external solution were replaced with tetraethylammonium chloride and $\mathrm{CsCl}$, respectively.

The transient outward current $\left(I_{\mathrm{to}}\right)$ was studied with a double-pulse protocol. A 30-ms prepulse from -80 to $-40 \mathrm{mV}$ was used to inactivate the sodium channels, followed by a $300-\mathrm{ms}$ test pulse to $+60 \mathrm{mV}$ in $10-\mathrm{mV}$ steps at a frequency of $0.1 \mathrm{~Hz} \cdot \mathrm{CdCl}_{2}(200 \mu \mathrm{M})$ was added to the bath solution to inhibit $I_{\mathrm{Ca}-\mathrm{L}}$. The $I_{\text {to }}$ was measured as the difference between the peak outward current and steady-state current. The ultra-rapid delayed rectifier potassium current $\left(I_{\text {Kur }}\right)$ was studied with a double-pulse protocol, consisting of a 100-ms depolarizing pre-pulse to $+40 \mathrm{mV}$ from a holding potential of $-50 \mathrm{mV}$, followed by 150 -ms voltage steps from -40 to $+60 \mathrm{mV}$ in $10 \mathrm{mV}$ increments at room temperature to provide an adequate temporal resolution. The $I_{\text {Kur }}$ was measured as 4-aminopyridine $(1 \mathrm{mM})$ sensitive currents.

The inward rectifier potassium current $\left(I_{\mathrm{K} 1}\right)$ was activated from $-40 \mathrm{mV}$ to test potentials ranging from -20 to $-120 \mathrm{mV}$ in $10-\mathrm{mV}$ steps for $1 \mathrm{~s}$ at a frequency of $0.1 \mathrm{~Hz}$ under the infusion of $\mathrm{CdCl}_{2}(200 \mu \mathrm{M})$ and 4-aminopyridine
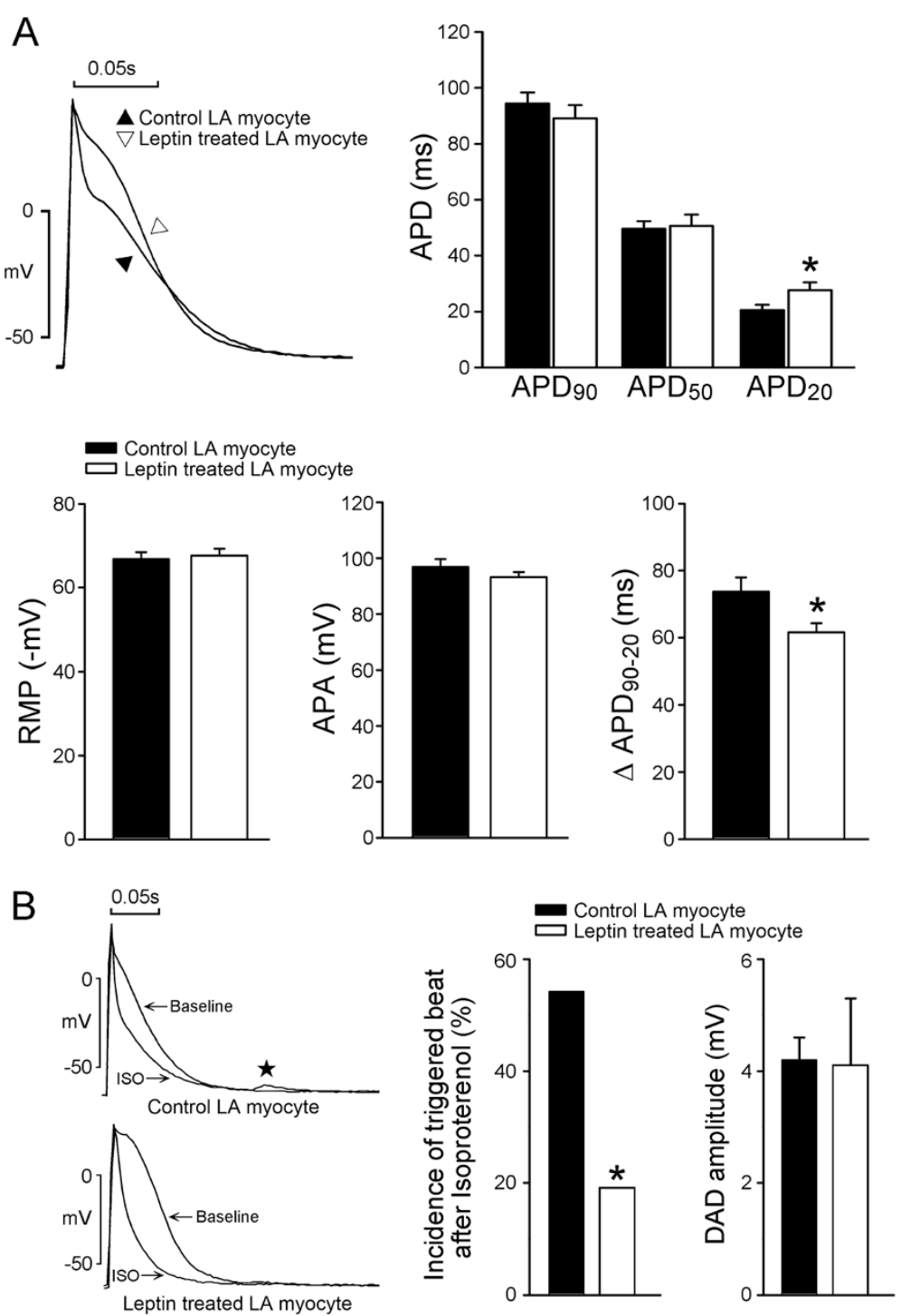

Figure 1 Effect of leptin on the left atrial (LA) electrical activity and effects of isoproterenol on control and leptin-treated left atrial (LA) myocytes. A. Examples and average data of the action potential from control $(n=22) L A$ myocytes and leptin-treated $L A$ myocytes $(n=19)$. Leptin-treated $L A$ myocytes had longer $A_{P D}$. B. Examples of isoproterenol-induced DAD $(\boldsymbol{\star})$ from control and leptin-treated LA myocytes. The incidence of isoproterenol-induced DADs from control $(n=24)$ and leptin-treated $(n=21)$ LA myocytes. RMP resting membrane potential, APA action potential amplitude, $\mathrm{APD}_{90} 90 \%$ action potential duration, $\mathrm{APD}_{50} 50 \%$ action potential duration, $\mathrm{APD}_{20} 20 \%$ action potential duration. ${ }^{*} \mathrm{p}<0.05$ versus control LA myocytes. 
$(2 \mathrm{mM})$ in the bath solution. The amplitudes of the $I_{\mathrm{K} 1}$ were measured as $1 \mathrm{mM}$ barium-sensitive currents.

The NCX current was elicited by test potentials between -100 to $+100 \mathrm{mV}$ from a holding potential of $-40 \mathrm{mV}$ for $300 \mathrm{~ms}$ at a frequency of $0.1 \mathrm{~Hz}$. The amplitudes of the NCX current were measured as $10 \mathrm{mM}$ nickel-sensitive currents. The external solution (in $\mathrm{mM}$ ) consisted of $\mathrm{NaCl} 140, \mathrm{CaCl}_{2} 2, \mathrm{MgCl}_{2}$ 1, HEPES 5 and glucose 10 with a $\mathrm{pH}$ of 7.4 and contained strophanthidin $(10 \mu \mathrm{M})$, nitrendipine $(10 \mu \mathrm{M})$ and niflumic acid $(100 \mu \mathrm{M})$.

\section{Measurement of the changes in the intracellular calcium concentration}

The intracellular $\mathrm{Ca}^{2+}\left(\mathrm{Ca}^{2+}{ }_{i}\right)$ was recorded using a fluorimetric ratio technique (indo-1 fluorescence) in an isolated single leptin-treated and control LA myocyte, as described previously [31,32]. The fluorescent indicator indo- 1 was loaded by incubating the myocytes at room temperature for $20-30 \mathrm{~min}$ with $10 \mu \mathrm{M}$ of indo-1/AM (Sigma Chemical, St Louis, MO, USA). LA myocytes were then perfused with Tyrode's solution at $35 \pm 1^{\circ} \mathrm{C}$ for at least $20 \mathrm{~min}$ to wash out the extracellular indicator and to allow for the intracellular de-esterification of the indo-1. The background and cell autofluorescence were canceled out by zeroing the output of the photomultiplier tubes using cells without indo-1 loading. A
UV light of $360 \mathrm{~nm}$ with a monochromator was used for the excitation of the indo- 1 from a xenon arc lamp controlled by the microfluorimetry system (OSP100-CA, Olympus, Tokyo, Japan) and the excitation light beam was directed into an inverted microscope (IX-70, Olympus, Tokyo, Japan). The emitted fluorescence signals from the indo-1/AM loaded myocytes were digitized at $200 \mathrm{~Hz}$. The ratio of the fluorescence emission at 410 and $485 \mathrm{~nm}$ (R410/485) was used as the index of the $\mathrm{Ca}^{2+}{ }_{i}$. This approach avoided any uncertainties resulting from the calibration of the fluorescent $\mathrm{Ca}^{2+}$ indicators. The $\mathrm{Ca}^{2+}{ }_{i}$ transients were measured during a $2 \mathrm{~Hz}$ field stimulation with $10 \mathrm{~ms}$ square-wave pulses at double threshold strength and were calculated from the difference of the peak systolic and diastolic $\mathrm{Ca}^{2+}{ }_{i}$ transients. The fluorescence ratio data were processed and stored on a computer using the relevant software (OSP-SFCA, Olympus, Tokyo, Japan). The sarcoplasmic reticulum (SR) $\mathrm{Ca}^{2+}$ content was estimated by adding $20 \mathrm{mM}$ of caffeine after electric stimulation at $2 \mathrm{~Hz}$ for at least $30 \mathrm{~s}$. The total $\mathrm{SR} \mathrm{Ca}^{2+}$ content was measured from the peak amplitude of the caffeineinduced $\mathrm{Ca}^{2+}{ }_{i}$ transients. We also measured the $\mathrm{SR} \mathrm{Ca}^{2+}$ content by integrating the NCX current from rapidly adding $20 \mathrm{mM}$ of caffeine to the cells during rest with the membrane potential clamped to $-40 \mathrm{mV}$. The time integral of the NCX current was converted to amoles of $\mathrm{Ca}^{2+}$ released from the SR [31].

\section{A}
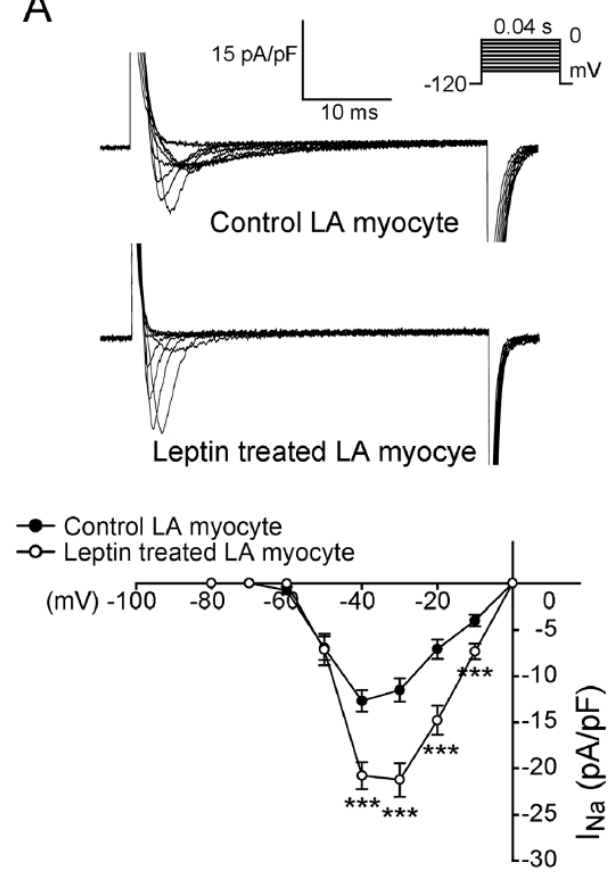

B
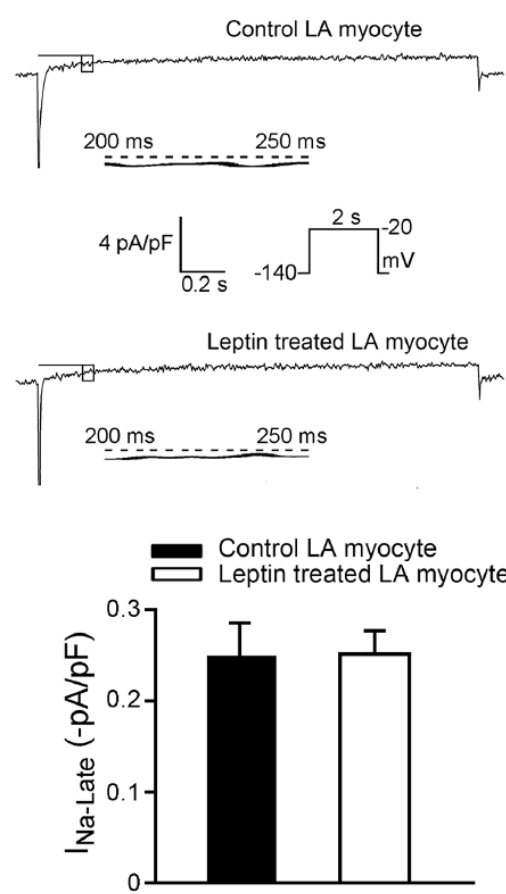

Figure 2 Effects of leptin on sodium current $\left(I_{\mathrm{Na}}\right)$ and late sodium current $\left(I_{\mathrm{Na}-L a t e}\right)$ in left atrial (LA) myocytes. A. Examples and the I-V relationship of the $I_{\mathrm{Na}}$ from control $(n=21)$ and leptin-treated $(n=14) L A$ myocytes. The insets in the current traces show the various clamp protocols. B. Examples and the average data of the $I_{\text {Na-Late }}$ in control $(n=8)$ and leptin-treated myocytes $(n=8)$. ${ }^{* *} p<0.005$ versus control LA myocytes. 


\section{Statistical analysis}

All continuous variables are expressed as the mean \pm SEM. The differences between the control and the leptin-treated LA myocytes were compared using the Mann-Whiteney rank sum test or unpaired $t$-test depending on the outcome of the normality test. A p value of less than 0.05 was considered statistically significant.

\section{Results}

Effects of leptin on the electrical activity of LA myocytes Figure 1A shows the AP morphology from the control and the leptin-treated LA myocytes. The leptin-treated LA myocytes had longer $\mathrm{APD}_{20}$, but similar $\mathrm{APD}_{50}$, $\mathrm{APD}_{90}$, and RMP, compared to the control. Moreover, the difference between $\mathrm{APD}_{90}$ and $\mathrm{APD}_{20}\left(\triangle \mathrm{APD}_{90-20}\right)$ was smaller in the leptin-treated LA myocytes than in the control LA myocytes. In the presence of isoproterenol (10 nM), leptin- treated LA myocytes exhibited a lower incidence of DADs than the control myocytes (Figure 1B).

\section{Effects of leptin on the membrane currents of LA myocytes}

Compared to the control LA myocytes, the leptintreated LA myocytes exhibited larger $I_{\mathrm{Na}}$ (Figure 2A) with a $46 \%$ increase of peak current (elicited from -120 to $-40 \mathrm{mV}$ ). Both the control and the leptin-treated LA myocytes exhibited similar $I_{\mathrm{Na}-\text { Late }}$ (Figure $2 \mathrm{~B}$ ) and

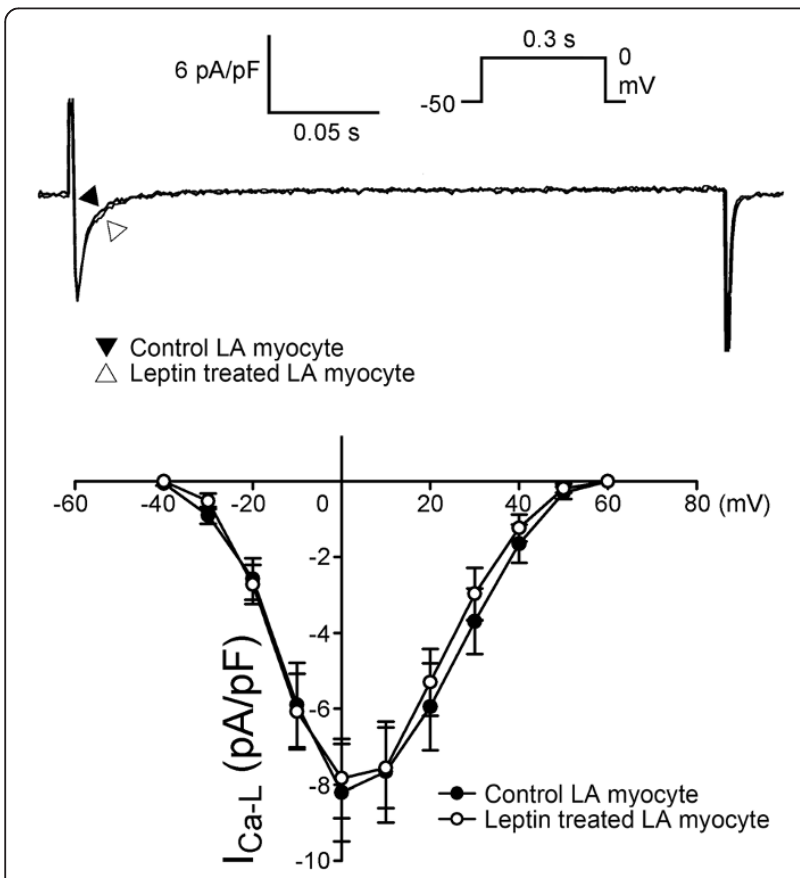

Figure 3 Effects of leptin on the L-type calcium channel $\left(I_{\mathrm{Ca}-\mathrm{L}}\right)$ in left atrial (LA) myocytes. The current traces and $I-V$ relationship of $I_{\text {Ca-L }}$ from control $(n=14)$ and leptin-treated $(n=10)$ LA myocytes. The insets in the current traces show the various clamp protocols. similar $I_{\mathrm{Ca}-\mathrm{L}}$ (Figure 3 ). The forward and reverse mode of NCX currents were smaller in the leptin-treated LA myocytes (Figure 4) than in the control myocytes with a $37.6 \%$ decrease in peak current (elicited from -40 to $-100 \mathrm{mV}$ ) in the forward mode and a $51 \%$ decrease in peak current (elicited from -40 to $100 \mathrm{mV}$ ) in the reverse mode.

As compared to the control myocytes, the leptintreated LA myocytes exhibited similar $I_{\text {to }}$, but smaller $I_{\text {Kur }}$ with a $32 \%$ decrease of peak current (elicited from -50 to $60 \mathrm{mV}$ ) (Figure 5A and 5B). The leptin-treated and control myocytes exhibited similar $I_{\mathrm{K} 1}$ (Figure 5C).

\section{Effects of leptin on calcium handling of LA myocytes}

As shown in Figure 6A, the leptin-treated LA myocytes exhibited a smaller amplitude of $\mathrm{Ca}^{2+}{ }_{i}$ transients than the control myocytes. In addition, the leptin-treated LA myocytes exhibited a smaller caffeine-induced $\mathrm{Ca}^{2+}{ }_{i}$ transients than the control myocytes, which was in consistent with a reduced sarcoplasmic reticulum (SR) $\mathrm{Ca}^{2+}$ content from integrating caffeine-induced NCX current in the leptin-treated LA myocytes (Figure 6B).

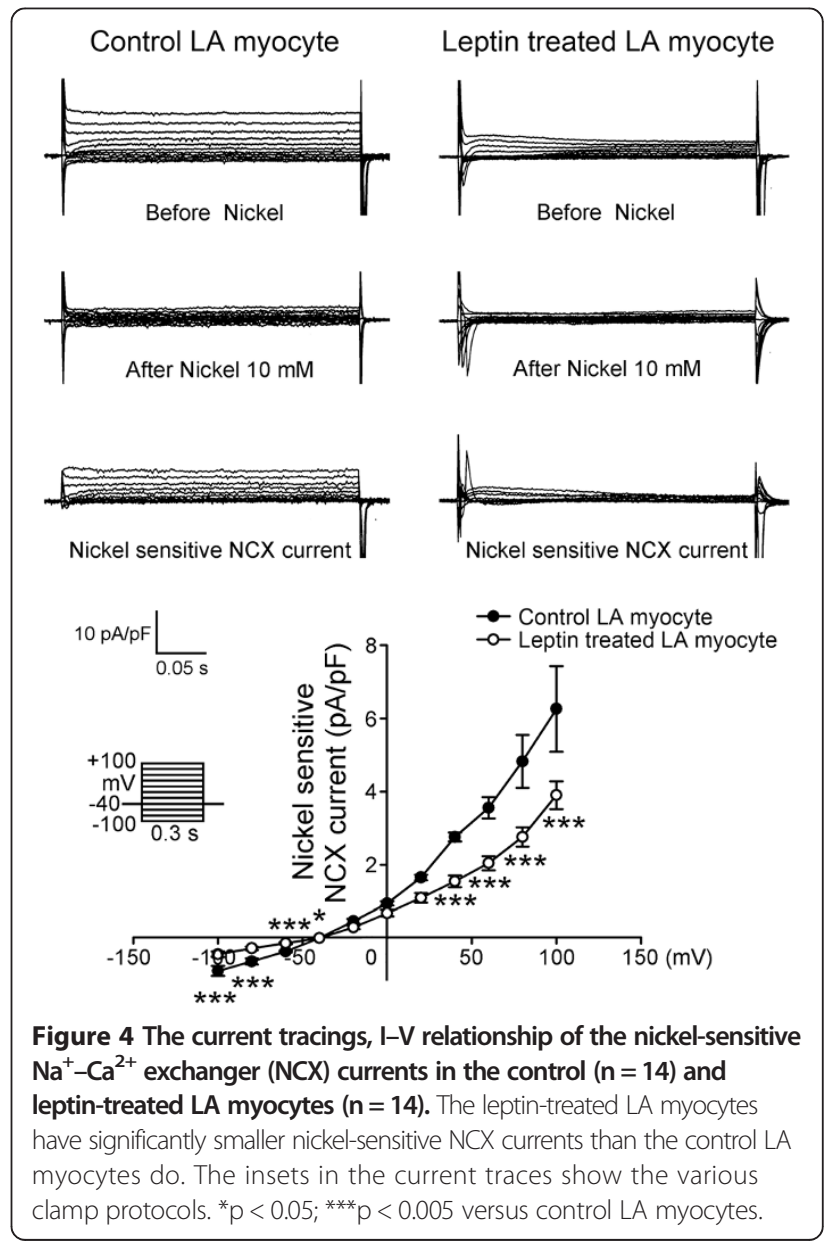




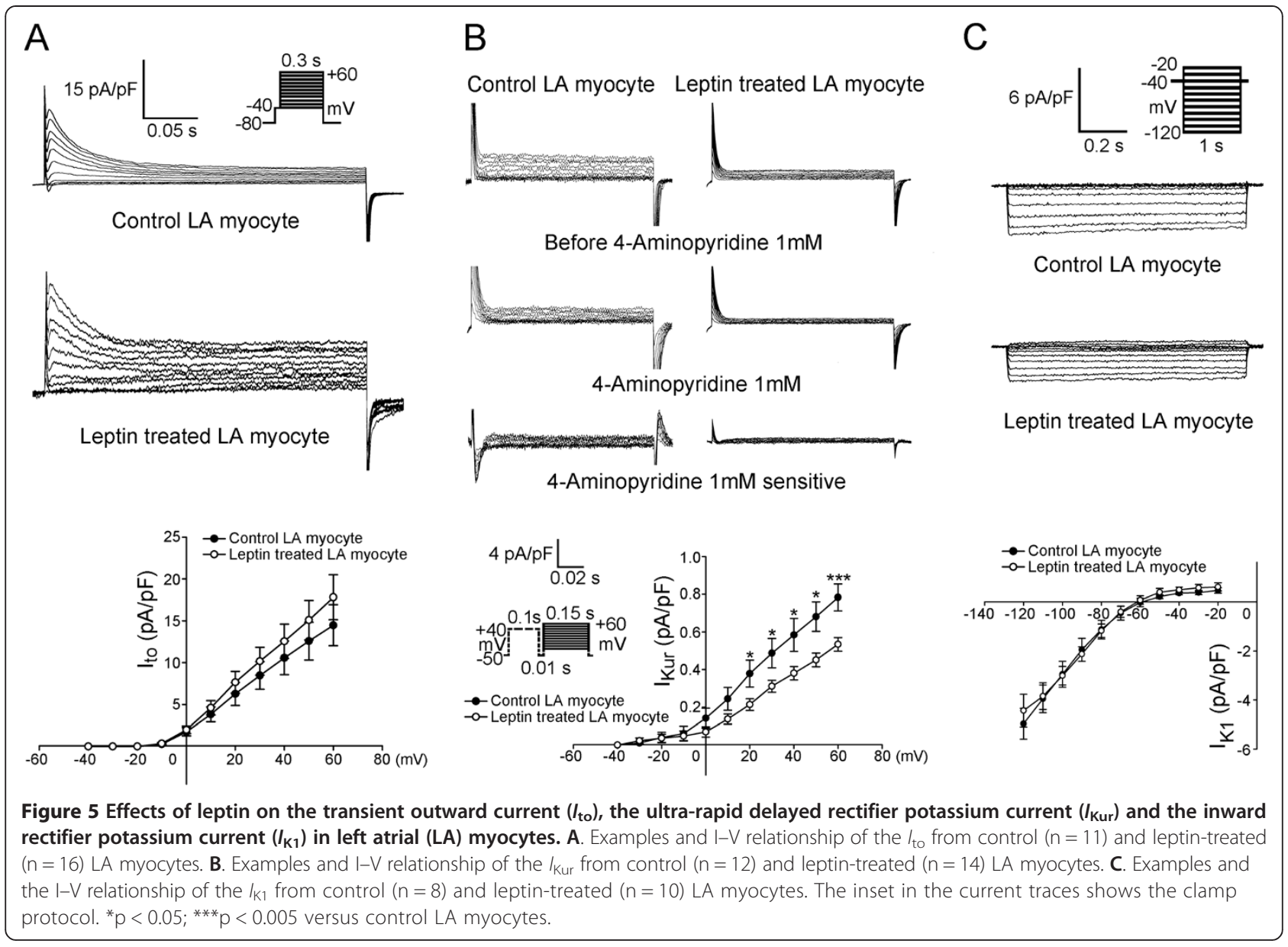

\section{Discussion}

Obesity is characterized by leptin resistance, which is additionally associated with chamber dilatation, dysfunction and increased risk of heart failure [33]. Adipose tissue is a large endocrine organ that secretes numerous adipokines. The effects of leptin on the heart are more pronounced in cases of metabolic syndrome or obesity, where it primarily acts systemically in visceral fat or acts locally through either direct interactions or through paracrine mechanisms in pericardial fat [10-12]. Leptin, one of the adipokines, is secreted by adipocytes as well as by cardiomyocytes and endothelial cells [13-16]. Leptin may regulate the physiology of the heart including myocyte contractility and metabolism [30], which both influences cardiac electrophysiology.

In this study, we found that leptin-treated LA myocytes had a longer $\mathrm{APD}_{20}$ and a shorter $\triangle \mathrm{APD}_{90-20}$. The inhomogeneously prolonged AP duration (triangulation) had been proposed as an arrhythmogenic factor [34]. Therefore, the increase of $\mathrm{APD}_{20}$ and the decrease of $\triangle \mathrm{APD}_{90-20}$ may provide an anti-arrhythmic effect by reverse-triangulation of AP. Additionally, as compared to the control, we observed that leptin- treated LA myocytes exhibited a lower incidence of isoproterenolinduced DAD than the control did, which suggests that leptin has potential anti-arrhythmic effects. Isoproterneol has been shown to increase several potassium currents [35-37], which can result in the shortening of AP duration in control and leptin-treated myocytes. However, a previous study had revealed that epicardial fat can prolong the AP duration, and positively shift RMP, and increased isoproterenol-induced arrhythmogenesis [11]. Our findings suggest that leptin may not be responsible for arrhythmogenesis of adipose tissue. In contrast, we propose that leptin attenuates the effects of adipose arrhythmogenesis. Obesity amplifies the production of multiple adipokines, and it is possible that adipokines may offset the anti-arrhythmogeneic potentials of leptin, thereby increasing the risks of AF in obesity. In addition, leptin resistance has been suggested to impair the beneficial effects of leptin [38].

We found that the $I_{\mathrm{Na}}$ current density in the leptintreated LA myocytes was significantly larger than that of the control LA myocytes. Increasing fast $I_{\mathrm{Na}}$ may improve conduction properties in cardiac cells, and thus reduce the risk of conduction block [39]. In contrast, the 

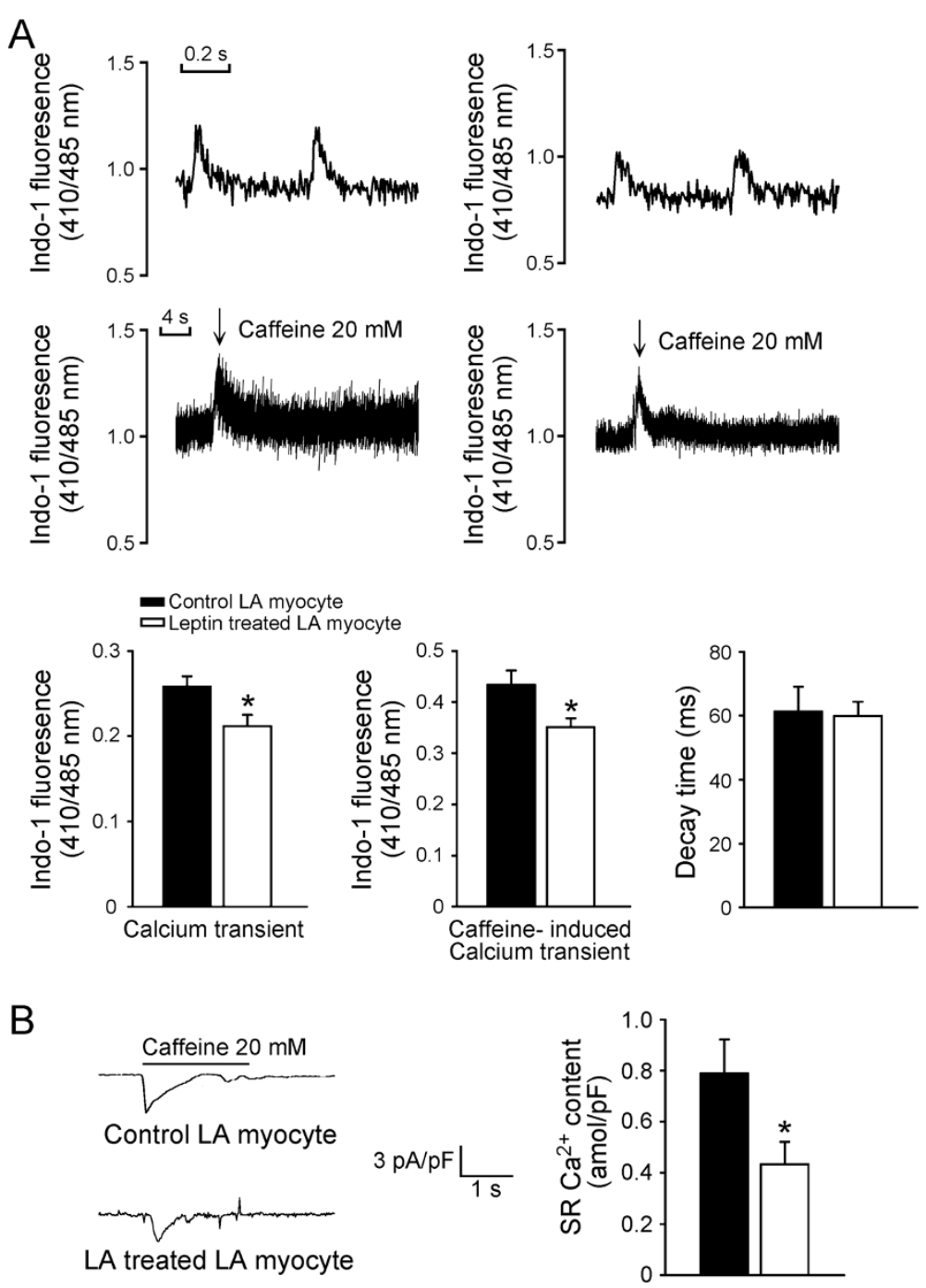

Figure 6 Effects of leptin on the intracellular $\mathrm{Ca}^{2+}$ and sarcoplasmic reticulum $\mathrm{Ca}^{2+}$ content of the LA myocytes. A. The tracings and average data from the $\mathrm{Ca}^{2+}$ transient and caffeine-induced $\mathrm{Ca}^{2+}$ transient in the control $(n=42)$ and leptin-treated LA myocytes $(n=38)$. B. The tracings of the caffeine-induced NCX currents and average data of SR Ca ${ }^{2+}$ content from integrating the NCX current in the control $(n=15)$ and leptin-treated LA myocytes $(n=11)$. ${ }^{*} p<0.05$ versus the control.

$I_{\text {Na-Late }}$ was similar between the control and leptintreated LA myocytes. $I_{\mathrm{Na}-\mathrm{Late}}$ was demonstrated to play a vital role in the arrhythmogenic potentials of the atria [40]. The larger $I_{\mathrm{Na}}$ but similar $I_{\mathrm{Na}-L a t e}$ in leptin-treated LA myocytes suggests a favorable role of leptin on atrial arrhythmogenesis.

NCX plays a critical role in the atrial arrhythmogenesis [41]. In this study, we found that leptin-treated LA myocytes exhibited reduced NCX. The leptin-treated LA myocytes also exhibited smaller $\mathrm{Ca}^{2+}{ }_{i}$ transient and smaller SR content than the control myocytes, which was in consistent with the known effects of leptin on ventricular myocytes [30]. The observed $\mathrm{Ca}^{2+}{ }_{i}$ transient and $\mathrm{SR} \mathrm{Ca}^{2+}$ content reduction in leptin-treated LA myocytes may be caused by the suppression of NCX with leptin. Leptin has been shown to increase the production of nitric oxide [42], which exerts cardiacdepressive actions. Therefore, the nitric oxide-mediated electrophysiological effect plays a role in leptin's reduction of $\mathrm{Ca}^{2+}{ }_{i}$ transient and SR Ca ${ }^{2+}$ content. Furthermore, the effects of leptin on calcium regulations may attenuate the isoproterenol-induced arrhythmogenesis by decreasing the genesis of the DAD.

$I_{\text {Kur }}$ are atrial specific ionic currents and plays an important role in atrial arrhythmogenesis [43]. We found that the leptin-treated LA exhibited smaller $I_{\text {Kur }}$ which may produce a larger $\mathrm{APD}_{20}$ and a smaller $\triangle \mathrm{APD}_{90-20}$. These effects may also contribute to an anti-AF potential. However, the $I_{\mathrm{K} 1}$ was similar between the control and the leptin-treated LA myocytes, which may account 
for the similar RMP in these cells. Although adult rat ventricular myocytes incubated with leptin $(100 \mathrm{ng} / \mathrm{ml})$ for 48 hours have been shown to increase the expressions of $I_{\mathrm{to}} \alpha$-subunits $(\mathrm{Kv} 4.2, \mathrm{Kv} 4.3)$ and $\mathrm{Kv}$ channel interacting protein (KChIP2), this study found that incubation of leptin at $100 \mathrm{nM}$ for a short period did not change $I_{\text {to }}$ in atrial myocytes [44].

\section{Potential limitations}

The data in this study should be interpreted with caution because of its potential limitations. First, similar to those in the previous studies, this short-period experiment has used a supra-physiological concentration $(100 \mathrm{nM})$ of leptin, which is higher than the clinically relevant concentrations [30]. The supra-physiological level of leptin may potentially reduce body weight through systemic administration of leptin in animal experiments [45,46]. Second, the incubation time was only $1 \mathrm{~h}$, which represents an acute effect of leptin. A longer incubation time might yield distinct results. In addition, only healthy atria tissue was used in this study, the results may differ in diseased atrial tissues. Finally, the underling molecular mechanisms for the electrophysiological effects were not elucidated in this study. JAK/STAT signaling had been suggested to play a role in the cardiac effects of leptin [47,48]. However, it is not clear whether the prolongation of $\mathrm{APD}_{20}$ or the increase of $I_{\mathrm{Na}}$ can be blocked by JAK2 inhibition.

\section{Conclusions}

Leptin regulates the LA electrophysiological characteristics and calcium homeostasis. Leptin attenuates the effect of isoproterenol-induced arrhythmogenesis, which may play a favorable role in the pathophysiology of atrial arrhythmogenesis.

\section{Competing interests}

The authors declare that they have no competing interests.

\section{Authors' contributions}

YKL interpreted the data and drafted the manuscript. YCC, JHH, and YJL performed the experiments and revised it for scientific content. SSH, SAC and YJC conceived of this study, and participated in its design and coordination. All authors read and approved the final manuscript.

\section{Acknowledgements}

The current study was supported by grants from National Science Council of Taiwan (NSC99-2314-B-016-034-MY3, NSC99-2628-B-038-011-MY3, NSC100-2628-B038-001-MY4, NSC100-2325-B-010-005, and NSC100-2314-B-038-027-MY3), Wan Fang Hospital (100-wf-eva-01, 100-wfeva-12, 100-swf-01, 100-swf-06, 101-wf-eva-11 and 101-wf-phd-01), and Taipei Veterans General Hospital (V100C-109, V101C-060),

\section{Author details}

'Division of Cardiovascular Medicine, Department of Internal Medicine, Wan Fang Hospital, Taipei Medical University, 111, Hsin-Lung Road, Sec. 3, Taipei, Taiwan. ${ }^{2}$ Graduate Institute of Clinical Medicine, College of Medicine, Taipei Medical University, Taipei, Taiwan. ${ }^{3}$ Department of Biomedical Engineering, National Defense Medical Center, Taipei, Taiwan. ${ }^{4}$ National Yang-Ming University, School of Medicine, Division of Cardiology and Cardiovascular Research Center, Veterans General Hospital-Taipei, Taipei, Taiwan. ${ }^{5}$ Department of Pharmacology and Institute of Medicine, Chung Shan Medical University,
Taichung, Taiwan. ${ }^{6}$ Department of Pharmacy, Chung Shan Medical University Hospital, Taichung, Taiwan.

Received: 13 September 2013 Accepted: 12 December 2013

Published: 20 December 2013

\section{References}

1. Wang TJ, Parise H, Levy D, D'Agostino RB Sr, Wolf PA, Vasan RS, Benjamin EJ: Obesity and the risk of new-onset atrial fibrillation. JAMA 2004, 292:2471-2477.

2. Tsang TS, Barnes ME, Miyasaka Y, Cha SS, Bailey KR, Verzosa GC, Seward JB, Gersh BJ: Obesity as a risk factor for the progression of paroxysmal to permanent atrial fibrillation: a longitudinal cohort study of 21 years. Eur Heart J 2008, 29:2227-2233

3. Dublin S, French B, Glazer NL, Wiggins KL, Lumley T, Psaty BM, Smith NL, Heckbert SR: Risk of new-onset atrial fibrillation in relation to body mass index. Arch Int Med 2006, 166:2322-2328.

4. Wanahita N, Messerli FH, Bangalore S, Gami AS, Somers VK, Steinberg JS: Atrial fibrillation and obesity - results of a meta-analysis. Am Heart J 2008, 155:310-315.

5. Tsang TS, Gersh BJ: Atrial fibrillation: An old disease, a new epidemic. Am $J$ Med 2002, 113:432-435.

6. Hubert HB, Feinleib M, McNamara PM, Castelli WP: Obesity as an independent risk factor for cardiovascular disease: a 26-year follow-up of participants in the Framingham Heart Study. Circulation 1983, 67:968-977.

7. Kenchaiah S, Evans JC, Levy D, Wilson PW, Benjamin EJ, Larson MG, Kannel WB, Vasan RS: Obesity and the risk of heart failure. N Engl J Med 2002, 347:305-313.

8. Murphy NF, Maclntyre K, Stewart S, Hart CL, Hole D, McMurray JJ: Longterm cardiovascular consequences of obesity: 20-year follow-up of more than 15,000 middle aged men and women (the Renfrew-Paisley study). Eur Heart J 2006, 27:96-106.

9. Watanabe H, Tanabe N, Watanabe T, Darbar D, Roden DM, Sasaki S, Aizawa $Y$ : Metabolic syndrome and risk of development of atrial fibrillation: the Niigata preventive medicine study. Circulation 2008, 117(10):1255-1260

10. Lin YK, Chen YJ, Chen SA: Potential atrial arrhythmogenicity of adipocytes: implications for the genesis of atrial fibrillation. Med Hypotheses 2010, 74:1026-1029.

11. Lin YK, Chen YC, Chen JH, Chen SA, Chen YJ: Adipocytes modulate the electrophysiology of atrial myocytes: implications in obesity-induced atrial fibrillation. Basic Res Cardiol 2012, 107(5):293.

12. Lin YK, Chen YC, Chang SL, Lin YJ, Chen JH, Yeh YH, Chen SA, Chen YJ: Heart failure epicardial fat increases atrial arrhythmogenesis. Int $J$ Cardiol 2013, 167(5):1979-1983.

13. Margetic S, Gazzola C, Pegg GG, Hill RA: Leptin: a review of its peripheral actions and interactions. Int J Obes Relat Metab Disord 2002, 26:1407-1433.

14. Unger RH: Lipotoxic diseases. Annu Rev Med 2002, 53:319-336.

15. Rajapurohitam V, Javadov S, Purdham DM, Kirshenbaum LA, Karmazyn M: An autocrine role for leptin in mediating the cardiomyocyte hypertrophic effects of angiotensin II and endothelin-1. J Mol Cell Cardiol 2006, 41 (2):265-274.

16. Purdham DM, Zou MX, Rajapurohitam V Karmazyn M: Rat heart is a site of leptin production and action. Am J Physiol Heart Circ Physiol 2004, 287(6):H2877-H2884.

17. Hosoda K, Masuzaki H, Ogawa Y, Miyawaki T, Hiraoka J, Hanaoka I, Yasuno A, Nomura T, Fujisawa Y, Yoshimasa Y, Nishi S, Yamori Y, Nakao K: Development of radioimmunoassay for human leptin. Biochem Biophys Res Commun 1996, 16:234-239.

18. Rosenbaum M, Nicolson M, Hirsch J, Heymsfield SB, Gallagher D, Chu F, Leibel RL: Effects of gender, body composition, and menopause on plasma concentrations of leptin. J Clin Endocrinol Metab 1996, 81:3424-3427.

19. Agata J, Masuda A, Takada M, Higashiura K, Murakami H, Miyazaki Y, Shimamoto K: High plasma immunoreactive leptin level in essential hypertension. Am J Hypertens 1997, 10:1171-1174.

20. Wallace AM, McMahon AD, Packard CJ, Kelly A, Shepherd J, Gaw A, Sattar N: Plasma leptin and the risk of cardiovascular disease in the west of Scotland coronary prevention study (WOSCOPS). Circulation 2001, 104(25):3052-3056

21. Schulze PC, Kratzsch J, Linke A, Schoene N, Adams V, Gielen S, Erbs S, Moebius-Winkler S, Schuler G: Elevated serum levels of leptin and soluble 
leptin receptor in patients with advanced chronic heart failure. Eur J Heart Fail 2003, 5(1):33-40.

22. Couillard C, Lamarche B, Mauriege P, Cantin B, Dagenais GR, Moorjani S, Lupien PJ, Després JP: Leptinemia is not a risk factor for ischemic heart disease in men. Prospective results from the Quebec Cardiovascular Study. Diabetes Care 1998, 21:782-786.

23. Schafer K, Halle M, Goeschen C, Dellas C, Pynn M, Loskutoff DJ, Konstantinides S: Leptin promotes vascular remodeling and neointimal growth in mice. Arterioscler Thromb Vasc Biol 2004, 24:112-117.

24. Rajapurohitam V, Gan XT, Kirshenbaum LA, Karmazyn M: The obesityassociated peptide leptin induces hypertrophy in neonatal rat ventricular myocytes. Circ Res 2003, 93:277-279.

25. Barouch LA, Berkowitz DE, Harrison RW, O'Donnell CP, Hare JM: Disruption of leptin signaling contributes to cardiac hypertrophy independently of body weight in mice. Circulation 2003, 108:754-759.

26. Werner N, Nickenig G: From fat fighter to risk factor: the zigzag trek of leptin. Arterioscler Thromb Vasc Biol 2004, 24:7-9.

27. Sierra-Honigmann MR, Nath AK, Murakami C, García-Cardeña G, Papapetropoulos A, Sessa WC, Madge LA, Schechner JS, Schwabb MB, Polverini PJ, Flores-Riveros JR: Biological action of leptin as an angiogenic factor. Science 1998, 281:1683-1686.

28. Sader S, Nian M, Liu P: Leptin: a novel link between obesity, diabetes, cardiovascular risk, and ventricular hypertrophy. Circulation 2003, 108(6):644-646.

29. Fukui A, Takahashi N, Nakada C, Masaki T, Kume O, Shinohara T, Teshima Y, Hara M, Saikawa T: Role of leptin signaling in the pathogenesis of angiotensin II - mediated atrial fibrosis and fibrillation. Circ Arrhythm Electrophysiol 2013, 6(2):402-409.

30. Nickola MW, Wold LE, Colligan PB, Wang GJ, Samson WK, Ren J: Leptin attenuates cardiac contraction in rat ventricular myocytes. Role of NO. Hypertension 2000, 36:501-505.

31. Suenari K, Chen YC, Kao YH, Cheng CC, Lin YK, Chen YJ, Chen SA: Discrepant electrophysiological characteristics and calcium homeostasis of left atrial anterior and posterior myocytes. Basic Res Cardiol 2011, 106(1):65-74.

32. Tsao HM, Weerateerangkul $P$, Chen YC, Kao YH, Lin YK, Huang JH, Chen SA, Chen YJ: Amyloid peptide regulates calcium homoeostasis and arrhythmogenesis in pulmonary vein cardiomyocytes. Eur J Clin Invest 2012, 42(6):589-598.

33. Balistreri CR, Caruso C, Candore G: The role of adipose tissue and adipokines in obesity-related inflammatory diseases. Mediators Inflamm 2010, 2010:802078.

34. Hondeghem LM, Carlsson L, Duker G: Instability and triangulation of the action potential predict serious proarrhythmia, but action potential duration prolongation is antiarrhythmic. Circulation 2001, 103:2004-2013.

35. Chen YJ, Chen SA, Chen YC, Yeh HI, Chang MS, Lin Cl: Electrophysiology of single cardiomyocytes isolated from rabbit pulmonary veins: implication in initiation of focal atrial fibrillation. Basic Res Cardiol 2002, 97(1):26-34.

36. Li GR, Feng J, Wang Z, Fermini B, Nattel S: Adrenergic modulation of ultrarapid delayed rectifier $\mathrm{K}+$ current in human atrial myocytes. Circ Res 1996, 78(5):903-915.

37. Su MJ, Chi JF, Chu SH: Adrenergic modulation of potassium currents in isolated human atrial myocytes. J Biomed Sci 1994, 1(3):193-200.

38. Beltowski J: Leptin and atherosclerosis. Atherosclerosis 2006, 189(1):47-60.

39. Clancy CE, Kass RS: Inherited and acquired vulnerability to ventricular arrhythmias: cardiac Na + and K + channels. Physiol Rev 2005, 85(1):33-47.

40. Belardinelli L, Shryock JC, Fraser H: Inhibition of the late sodium current as a potential cardioprotective principle: effects of the late sodium current inhibitor ranolazine. Heart 2006, 92:iv6-iv14

41. Wongcharoen W, Chen YC, Chen YJ, Chang CM, Yeh HI, Lin Cl, Chen SA: Effects of a $\mathrm{Na}+/ \mathrm{Ca} 2+$ exchanger inhibitor on pulmonary vein electrical activity and ouabain-induced arrhythmogenicity. Cardiovasc Res 2006, 70(3):497-508

42. Fruhbeck G: Pivotal role of nitric oxide in the control of blood pressure after leptin administration. Diabetes 1999, 48:903-908.

43. Wettwer E, Hála O, Christ T, Heubach JF, Dobrev D, Knaut M, Varró A, Ravens U: Role of IKur in controlling action potential shape and contractility in the human atrium: influence of chronic atrial fibrillation. Circulation 2004, 110(16):2299-2306.

44. Gómez-Hurtado N, Fernández-Velasco M, Fernández-Alfonso MS, Boscá L, Delgado C: Prolonged leptin treatment increases transient outward K+ current via upregulation of Kv4.2 and Kv4.3 channel subunits in adult rat ventricular myocytes. Pflugers Arch 2013. in press, doi:10.1007/s00424-013-1348-3.

45. Sanigorski A, Cameron-Smith D, Lewandowski P, Walder K, de Silva A, Morton G, Collier GR: Impact of obesity and leptin treatment on adipocyte gene expression in Psammomys obesus. J Endocrinol 2000, 164(1):45-50.

46. Stunes AK, Westbroek I, Gordeladze JO, Gustafsson BI, Reseland JE, Syversen $U$ : Systemic leptin administration in supraphysiological doses maintains bone mineral density and mechanical strength despite significant weight loss. Endocrinology 2012, 153(5):2245-2253.

47. Smith CC, Dixon RA, Wynne AM, Theodorou L, Ong SG, Subrayan S, Davidson SM, Hausenloy DJ, Yellon DM: Leptin-induced cardioprotection involves JAK/STAT signaling that may be linked to the mitochondrial permeability transition pore. Am J Physiol Heart Circ Physiol 2010, 299(4):H1265-H1270.

48. Wold LE, Relling DP, Duan J, Norby FL, Ren J: Abrogated leptin-induced cardiac contractile response in ventricular myocytes under spontaneous hypertension: role of Jak/STAT pathway. Hypertension 2002, 39(1):69-74.

doi:10.1186/1423-0127-20-94

Cite this article as: Lin et al:: Leptin modulates electrophysiological characteristics and isoproterenol-induced arrhythmogenesis in atrial myocytes. Journal of Biomedical Science 2013 20:94.

\section{Submit your next manuscript to BioMed Central and take full advantage of:}

- Convenient online submission

- Thorough peer review

- No space constraints or color figure charges

- Immediate publication on acceptance

- Inclusion in PubMed, CAS, Scopus and Google Scholar

- Research which is freely available for redistribution
C) Biomed Central 